Fabián Gredig y Sebastián Claro, La Pregunta de la Reina: Lecciones de la Primera Crisis Económica Mundial del Siglo XXI (Prentice Hall, 2009).

\title{
COMENTARIO SOBRE LA PREGUNTA DE LA REINA (LECCIONES DE LA PRIMERA CRISIS ECONÓMICA MUNDIAL DEL SIGLO XXI) DE F. GREDIG Y S. CLARO
}

\section{Pablo E. Guidotti}

Fabián Gredig y Sebastián Claro han escrito un excelente libro sobre la crisis que afecta a la economía mundial desde mediados de 2007. En mi primer contacto con La Pregunta de la Reina: Lecciones de la Primera Crisis Económica Mundial del Siglo XXI, su título me resultó un tanto intrigante. Los autores pronto revelan en su prólogo que "la pregunta de la Reina" se refiere a un hecho inusual ocurrido en Inglaterra en octubre de 2008. Según relatan, luego de escuchar atentamente la exposición de un catedrático de la London School of Economics durante una visita a dicha universidad, la Reina Isabel II habría formulado una simple y a la vez profunda pregunta: “¿Por qué nadie notó que la crisis se estaba gestando?".

Gredig y Claro utilizan a la pregunta de la Reina como elemento organizador de un análisis serio, ordenado y parsimonioso de los orígenes y desarrollo de la crisis financiera internacional. Los autores comienzan con un capítulo dedicado a resumir las principales caracterís-

Pablo E. Guidotti. Doctor en Economía, Universidad de Chicago. Profesor Plenario, Universidad Torcuato Di Tella.

Palabras clave: crisis financiera; desbalances globales; política monetaria. 
ticas de la Gran Depresión de los años 1930 y, en especial, de la crisis financiera desatada en esa época en los Estados Unidos.

A continuación, sigue una breve pero completa descripción de las principales tendencias económicas de la economía de los Estados Unidos, con especial foco en las últimas dos décadas. Allí se enfatiza el significativo cambio de los Estados Unidos, que de país acreedor neto del resto del mundo ha llegado a transformarse en un país deudor neto. Este fenómeno, que refleja el surgimiento de grandes déficits en la cuenta corriente del balance de pagos desde mediados de la década de los 1990, es analizado de una manera muy efectiva por los autores. En particular, Gredig y Claro exponen con suma claridad la interrelación existente entre los cambios en la hoja de balance de los Estados Unidos con el fenómeno del apalancamiento - especialmente del sector privado no financiero- y la evolución del precio de los activos, tanto en el mercado bursátil como en el hipotecario.

Uno de los aspectos centrales de la evolución de la economía de los Estados Unidos en los años que preceden la crisis financiera se refiere al desarrollo del mercado de capitales y su creciente conexión con la actividad bancaria tradicional. Los autores dedican un capítulo del libro a explicar el proceso de innovación financiera que se manifiesta en la aparición de nuevos instrumentos de cobertura — tales como los credit default swaps - y en la virtual explosión de los mercados de activos titulizados (o securitizados). El rápido crecimiento de estos instrumentos revoluciona el mercado hipotecario norteamericano y, en especial, su tramo subprime.

Una cuestión fundamental en este proceso es el rol que le cupo a la política monetaria ejercida por la Reserva Federal durante la gestión de Alan Greenspan. ¿Fueron las bajas tasas de interés que prevalecieron en los Estados Unidos por más de una década decisivas a la hora de incentivar una desmedida (ex post) búsqueda por mayor rentabilidad vía un proceso de innovación financiera que escondía los verdaderos riesgos asociados con dicha actividad? Sin tomar partido por una causa específica, los autores muestran evidencia clara de cómo la innovación financiera, y sus distintas interconexiones, respondió en parte a un arbitraje regulatorio que permitió que la capitalización de los principales actores en los mercados financieros y de capitales fuera disminuyendo rápidamente en la última década y, por ende, aumentase la exposición de dichas instituciones al riesgo asociado con potenciales caídas en el precio de los activos. 
Una vez concluido el análisis de las principales tendencias económicas previas a la crisis, Gredig y Claro dedican dos capítulos del libro a una detallada descripción de la debacle financiera internacional que se desató a partir de mediados de 2007 con el anuncio de la quiebra de tres fondos de inversión operados por el banco francés BNP Paribas. El análisis de la crisis financiera internacional está dividido en dos etapas - que los autores denominan "de la euforia a la incertidumbre" y "de la incertidumbre al pánico" - con el propósito de mostrar la importancia que tuvo la decisión por parte de la Reserva Federal de dejar quebrar el banco de inversión Lehman Brothers en la dinámica de los eventos y en la aceleración del pánico financiero.

En estos capítulos — los más importantes del libro - se describen en detalle la dinámica de los mercados durante la crisis, los mecanismos de traspaso de riesgo tanto entre distintas clases de activos en instituciones como entre distintas regiones, así como la secuencia de acciones extraordinarias de política económica implementadas en ambos lados del Atlántico en respuesta a la crisis financiera. Los autores muestran cómo las acciones sin precedentes de los bancos centrales en las economías avanzadas son efectivas a la hora de destrabar el virtual congelamiento de los mercados financieros y de capitales de corto plazo cruciales para un adecuado manejo de la liquidez.

La estructura del libro descrita en los párrafos anteriores refleja un enfoque que se ha vuelto hoy "convencional" en el análisis de la crisis financiera internacional y sus causas. La línea argumental seguida por Gredig y Claro - comenzar con la Gran Depresión, identificar los factores causales de la crisis en los años previos a la crisis, y luego analizar de la crisis misma y las acciones de política - es la utilizada por la gran mayoría de los economistas y funcionarios en las economías avanzadas.

Sin embargo, al haberse vuelto convencional, esta línea argumental esconde un supuesto implícito que se transmite al lector sin mucha justificación: que la Gran Depresión es efectivamente el hito relevante con el cual cabe comparar la crisis financiera de 2007-2009. ¿Es realmente cierto que el mundo corrió el riesgo de repetir una crisis como la de los años treinta? Aunque en sus inicios la evolución de algunos agregados macroeconómicos fue similar a la ocurrida en los inicios de la Gran Depresión, esa similitud se desvaneció a los pocos meses, como bien indica Sebastián Edwards en su breve pero incisivo prólogo. Utilizar a la Gran Depresión como benchmark claramente coloca en un plano favorable a las acciones de política 
económica implementadas en los Estados Unidos y en Europa, en el sentido que al evitarse una nueva Gran Depresión las políticas económicas aplicadas deberían entonces ser calificadas como exitosas.

Gredig y Claro adoptan como propia esta visión convencional transmitida desde el Norte, sin transmitir necesidad alguna de evaluarla críticamente. Del mismo modo, los autores también exponen de una manera aséptica los distintos factores macroeconómicos —en particular los desbalances globales y la política monetaria seguida en la era Greenspan-, que contribuyeron a la gestación de la crisis, sin tomar posición sobre la importancia relativa de los mismos. Los autores prefieren hablar de una multiplicidad de factores sin necesidad de priorizar sobre la relevancia de los mismos.

Pero sabemos que las propuestas de política económica dependen crucialmente de la relevancia relativa otorgada a los distintos factores. Por ejemplo, existen en la actualidad dos grandes hipótesis sobre las causas de la crisis, que sin ser enteramente sustitutivas, sí llevan a conclusiones distintas con respecto a la agenda futura de política económica. Por un lado, existe una visión que enfatiza el rol de los factores macroeconómicos, en particular el de los denominados desbalances globales y la política monetaria de la era Greenspan, que al inducir tasas de interés excesivamente bajas por un tiempo muy prolongado generaron las condiciones para la gestación de burbujas especulativas y la toma excesiva de riesgo. En esta visión, los desbalances globales responden a un excesivo ahorro por parte de China y a un proceso ineficiente de acumulación de activos externos por parte de las economías emergentes o en desarrollo.

Por otro lado, existe otra visión que enfatiza el rol de la débil regulación y supervisión financiera y de los mercados de capitales como la causa primordial de la crisis financiera. Hoy resulta claro que el proceso de arbitraje regulatorio que llevó a las distintas entidades financieras y del mercado de capitales a aumentar rápidamente su apalancamiento $-\mathrm{o}$, lo que es lo mismo, a reducir su capital propio en relación a sus activos de riesgo - fue central a la hora de explicar el pánico y el congelamiento de los mercados monetarios y financieros en la crisis y la necesidad de acudir con fondos públicos al rescate de las entidades que presentaban un alto riesgo sistémico.

Para efectos de decidir la agenda de la política económica las prioridades que emergen de estas dos visiones son bien diferentes. La primera visión enfatiza respuestas de carácter macroeconómico, hoy ejemplificadas en el llamado que le hacen los Estados Unidos a China para que deje apreciar 
su moneda (el yuan) y en la búsqueda de mecanismos que incentiven una menor acumulación de reservas en las economías emergentes e induzcan un rebalanceo de la demanda agregada mundial. La segunda visión enfatiza la necesidad de un cambio significativo en la regulación y supervisión financiera, en parte reflejado en el denominado Acuerdo de Basilea III.

Encuentro que Gredig y Claro hacen un excelente trabajo en describir una gran cantidad de eventos y conceptos complejos en un lenguaje ágil y comprensible hasta para lectores que tienen muy poca formación financiera o económica. La claridad en la exposición refleja a su vez una gran claridad conceptual. Los autores no caen en la tentación de ser excesivamente detallistas o anecdóticos, y logran un libro muy recomendable que provee una descripción rigurosa, clara y amena de acontecimientos de singular importancia para la economía mundial actual.

Para el lector más ilustrado en los temas abordados en La Pregunta de la Reina: Lecciones de la Primera Crisis Económica Mundial del Siglo $X X 1$, hay sin embargo dos áreas que aparecen insuficientemente exploradas. Este comentario no es necesariamente crítico, sino más bien refleja la avidez del lector por ampliar un estimulante análisis que invita a una mayor profundización. En primer lugar, la discusión de los aspectos regulatorios $\mathrm{y}$ de supervisión tanto financiera como de los mercados de capitales es relativamente escueta, por lo que el capítulo final que abarca a los desafíos futuros deja al lector con sabor a más. En particular, dada la pertenencia de los autores al Banco Central de Chile, hubiese sido sumamente útil contar con su perspectiva acerca de cómo la crisis financiera internacional y las recientes reformas adoptadas en los Estados Unidos y en el marco del Comité de Basilea y el Financial Stability Board impactarán en los marcos regulatorios en materia financiera en América Latina.

En segundo lugar, los autores no utilizan su condición de observadores privilegiados y partícipes del debate de política económica para analizar las implicancias de la crisis financiera internacional sobre las economías emergentes y, en particular, sobre la economía de Chile. La política económica de Chile es, desde hace varios años, un ejemplo para América Latina y para las economías emergentes en general. Como lector, extrañé un capítulo que analizara el impacto de la crisis sobre la economía de Chile y evaluara la efectividad de la respuesta de su política fiscal y monetaria ante los desafíos puestos por el escenario externo. 